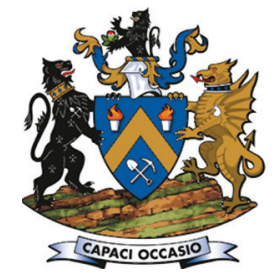

Affiliation:

${ }^{1}$ Department of Materials Science and Metallurgical Engineering, University of Pretoria, South Africa.

2GEFERTEC GmbH,Germany.

Correspondence to:

H. Möller

Email:

hein@heinmoller.co.za

Dates:

Received: 29 Jan. 2021

Revised: 15 Jul. 2021

Accepted: 21 Jul. 2021

Published: July 2021

How to cite:

Mashigo, L., Möller, H., and

Gassmann, C. 2021

Comparison of the

mechanical properties of Grade 5 and Grade 23 Ti6Al4V for wire-arc additive manufacturing. Journal of the Southern African Insitute of Mining and Metallurgy, vol. 121, no. 7, pp. 325-330

DOI ID:

http://dx.doi.org/10.17159/24119717/1498/2021

ORCID:

H. Möller

https://orcid.org/0000-0001-

6075-9965

L. Mashigo

https://orcid.org/0000-0002-

0391-2799

C. Gassmann

https://orcid.org/0000-0003-

3379-6618

\section{Comparison of the mechanical properties of Grade 5 and Grade 23 Ti6Al4V for wire-arc additive manufacturing}

\author{
L. Mashigo*1, H. Möller ${ }^{1}$, and C. Gassmann² \\ *Paper written on project work carried out in partial fulfilment of B.Eng \\ (Metallurgical Engineering) degree
}

\section{Synopsis}

Wire-arc additive manufacturing (WAAM) is a directed-energy deposition technology that uses arc welding procedures to produce computer-aided designed parts, such as three-dimensional printed metal components. A challenge of additive manufacturing is the anisotropy. Interstitial elements play a significant role in the mechanical properties of Ti6Al4V of different grades. In this research, the mechanical properties of Grade 5 and Grade $23 \mathrm{Ti} \mathrm{AAl} 4 \mathrm{~V}$ were compared for this application. Samples were extracted from WAAM-produced Ti6Al4V walls in different directions (horizontal and vertical) and at different positions (top and bottom). The samples were subjected to optical microscopy and tensile and hardness tests. Grade $5 \mathrm{Ti6 \textrm {Al }} 4 \mathrm{~V}$ samples were found to have greater strength, greater hardness, and lower ductility, owing to the higher content of interstitial elements compared with Grade 23 . The bottom samples had higher strength than the top samples, which is attributed to thermal cycling during manufacturing, resulting in different microstructures.

Keywords

Ti6Al4V, wire-arc additive manufacturing, anisotropy, heat accumulation, interstitial elements.

\section{Introduction}

Additive manufacturing has been growing exponentially in the fabrication industry since its inception in the 1980s. Conventionally, subtractive fabrication has been more broadly utilized, in which raw material is subjected to a machining process to remove unwanted material to produce the designed component (Li et al., 2019). Additive manufacturing, in contrast, has the advantage of decreasing the cost and time of manufacturing because it directly produces the designed component without wasting any material (Antonysamy, 2012).

\section{Wire-arc additive manufacturing (WAAM)}

of the diverse additive manufacturing procedures, wire-arc additive manufacturing (WAAM) has the advantage of manufacturing complex shapes with greater material usage efficiency, and has one of the highest deposition rates. WAAM is a directed-energy deposition procedure that employs arc welding to produce components using a three-dimensional (3D) metal printer (AMFG, 2018).

In the WAAM process, a component is designed using computer-aided design (CAD) software and the design is transferred to a 3D printing machine. A metal wire is melted onto a substrate using an electric arc as the heat source, and the component is manufactured in a layer-by-layer deposition process. After production, the printed component undergoes 3D geometrical scanning for quality control, followed by surface finishing (AMFG, 2018). WAAM-manufactured components have a high surface roughness and contain residual stresses and distortion because of the relatively high heat input (AMFG, 2018).

Other techniques of additive manufacturing have been used to produce metal components. The laser powder bed fusion (L-PBF) process is more prone to form defects, such as porosity (Thuketana et al., 2020), which is less likely with WAAM (Biswal et al., 2019). Benson (2012) addressed the risks associated with metal powders and safety considerations when handling them. Owing to their high surface-to-volume ratio, powders are naturally more reactive than bulk materials; and incorrect handling can potentially lead to fires and explosions. The wire used in the WAAM process is safer to handle than powder. 


\section{Comparison of the mechanical properties of Grade 5 and Grade 23 Ti6Al4V}

\section{Ti6Al4V}

Ti6Al4V is used in various industries and is the most studied titanium alloy in the additive manufacturing sector. It exhibits a good balance of strength, ductility, and fatigue resistance. Ti6Al4V comprises an aluminium-stabilized $\alpha$ phase and vanadium-stabilized $\beta$ phase (Carroll, Palmer, and Beese, 2015), and the transformation from $\beta$ to $\alpha$ plays a significant role in this alloy and affects the final microstructure. This transformation is most influenced by the cooling rate and alloy composition (Antonysamy, 2012).

\section{Microstructure}

The thermal history of a process determines the development of the phases in a structure, which in $\alpha+\beta$ Ti6Al4V can include primary $\alpha$, lathlike $\alpha$, colony $\alpha$, hcp martensite $\alpha\left(\alpha^{\prime}\right)$, grain boundary $\alpha$, acicular $\alpha$, and prior $\beta$ phases (Bintao et al., 2018). During WAAM, the titanium substrate is heated to its liquidus temperature as the Ti6Al4V wire melts at the fusion zone to form a weld bead. At the moment of heating, immediately below the fusion zone, $\alpha$ and $\beta$ grains in the substrate heterogeneously nucleate, return to the prior completely $\beta$ structure, and undergo faster grain growth. Grown $\beta$ grains at the edge of the fusion zone serve as nucleation sites at which the solidification front epitaxially grows back through to the weld pool, where coarsening grain structures form as a continuation of the grains around the fusion zone. Thus, in the next layer, $\beta$ grains keep growing from the coarse $\beta$ grains formed in the previous layer (Wang et al., 2012). The solidification process during WAAM of Ti6Al4V promotes the epitaxial growth of columnar grains. These columnar grains influence the tensile strength, affect the mechanical properties, and play a role in the tensile anisotropy that develops in the vertical and horizontal directions of the same specimen (Bermingham, McDonald, and Dargusch, 2018). Bintao et al. (2018) found that, although factors such as the solidification microstructure, grain size, and morphology are dependent on the thermal history during WAAM, heat accumulation also has an influence, therefore understanding the impact of heat accumulation can improve process control and optimization.

\section{Anisotropy}

Microstructural elements, such as $\beta$ grain size, the thickness of $\alpha$ grain boundaries, size of primary $\alpha$ grains, and the presence of martensitic $\alpha$ grains, play a role in the mechanical properties of Ti6Al4V (Wang et al., 2012). A study of anisotropy in the corrosion behaviour of Ti6Al4V produced by WAAM showed that the vertical plane had higher corrosion resistance than the horizontal plane (Wu et al., 2018). These values are influenced by the grain sizes and phase orientation in the planes. Zhang et al. (2016) identified anisotropy in a study of fracture toughness and fatigue crack growth rate in Ti6Al4V produced by WAAM. The vertical plane (across the layers) had higher fracture toughness than the horizontal plane (along the layers). Grade 23 Ti6Al4V also had higher fracture toughness than Grade 5 (Zhang et al., 2016).

\section{Grade 5 and Grade 23 Ti6Al4V}

The main difference between Grade 23 (also known as Ti6Al4V ELI) and Grade $5 \mathrm{Ti6Al4V}$ is the reduced content of interstitial elements in the former. Low interstitial element content improves ductility and fracture toughness, but reduces the strength of the alloy (Azom, 2002). Interstitial elements, such as oxygen and nitrogen, play a role in microstructures because they are strong $\alpha$-stabilizers and influence the $\alpha$-to- $\beta$ transition temperature (Antonysamy, 2012). Oxygen in titanium has a notable hardening effect (Bauristhene, Mutombo, and Stumpf, 2013; Oh, et al., 2011).

Considering the role of interstitial elements in influencing anisotropy, the objective of this study was to investigate the mechanical properties of Grade 5 and Grade 23 Ti6Al4V printed walls produced using WAAM, in different directions relative to the building direction and at different positions in the walls.

\section{Experimental methods}

\section{Wire-arc additive manufacturing}

Grade 5 and Grade 23 Ti6Al4V wires with a diameter of $1.2 \mathrm{~mm}$ were deposited to produce 3D printed walls with dimensions of $195 \mathrm{~mm} \times 125 \mathrm{~mm} \times 31 \mathrm{~mm}$ using 3DMP® technology (Gefertec, Germany). The process parameters are provided in Table I. The wires were deposited by the oscillation strategy, as shown in Figure 1. The walls were stress-relief heat-treated in a Xerion vacuum furnace at $650^{\circ} \mathrm{C}$ for 2.5 hours, followed by furnace cooling. Standard specifications of Ti6Al4V wires and chemical compositions of the wires are shown in Table II; photographs of the walls are shown in Figure 2.

\section{Metallographic preparation and microscopy}

Metallographic samples were prepared according to ASTM E3 requirements. Ti6Al4V samples cut from the walls were mounted and sequentially ground using P200, P600, P800, P1200, and P2500 SiC abrasive papers with water as the lubricant, polished using colloidal silica solution, and then etched using Kroll's reagent. An Olympus BX51M optical microscope was used to examine the microstructures at a magnification of 50xs.

\section{Hardness testing}

Sample hardness was measured using an HR-150A Vickers microhardness machine at a constant load of $2 \mathrm{~kg}$ force for 15 seconds.

\section{Tensile testing}

Flat tensile samples were extracted as shown in Figure 3a and machined using a xenon wire-cutting machine. They were extracted in the vertical (ZX) and horizontal (XY) planes, as

\section{Table I}

\section{Process parameters for WAAM deposition}

\begin{tabular}{|l|c|}
\hline Current & $180 \mathrm{~A}$ \\
Voltage & $16 \mathrm{~V}$ \\
Travel speed & $1.8 \mathrm{~m} / \mathrm{min}$ \\
Wire feed speed & $9.7 \mathrm{~m} / \mathrm{min}$ \\
\hline
\end{tabular}

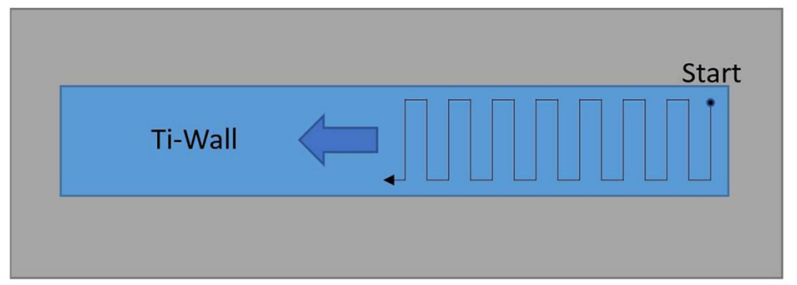

Figure 1-Schematic of the deposition strategy for WAAM Ti6AI4V walls 


\section{Comparison of the mechanical properties of Grade 5 and Grade 23 Ti6Al4V}

Table II

Standard specifications and chemical compositions of Ti6Al4V wires used in additive manufacturing (mass\%)

\begin{tabular}{|c|c|c|c|c|c|c|c|c|}
\hline & $\mathrm{Ti}$ & Al & V & $\mathrm{Fe}$ & C & 0 & $\mathbf{N}$ & H \\
\hline $\begin{array}{l}\text { Grade } 5 \text { (ASTM B863 - 19) } \\
\text { Grade } 23 \text { (ASTM B863 - 19) } \\
\text { Grade } 5 \\
\text { Grade } 23\end{array}$ & $\begin{array}{l}\text { Bal. } \\
\text { Bal. } \\
\text { Bal. } \\
\text { Bal. }\end{array}$ & $\begin{array}{c}5.5-6.75 \\
5.5-6.5 \\
5.7 \\
6.225\end{array}$ & $\begin{array}{c}3.5-4.5 \\
3.5-4.5 \\
4.15 \\
3.95\end{array}$ & $\begin{array}{c}<0.25 \\
<0.25 \\
0.125 \\
0.13\end{array}$ & $\begin{array}{l}<0.08 \\
<0.08 \\
0.015 \\
0.006\end{array}$ & $\begin{array}{c}<0.20 \\
<0.13 \\
0.17 \\
0.04\end{array}$ & $\begin{array}{c}<0.05 \\
<0.03 \\
0.01 \\
0.003\end{array}$ & $\begin{array}{l}<0.015 \\
<0.013 \\
0.0012 \\
0.0011\end{array}$ \\
\hline
\end{tabular}

(a)

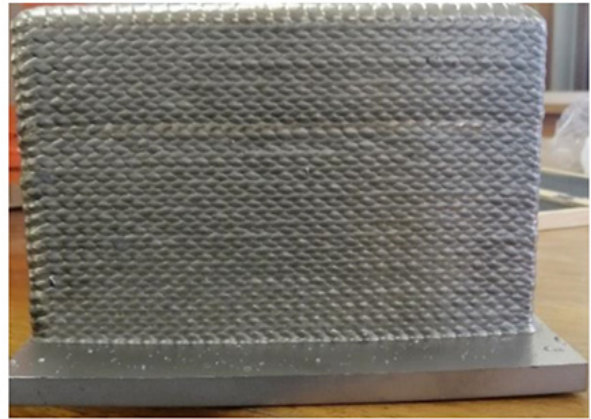

(b)

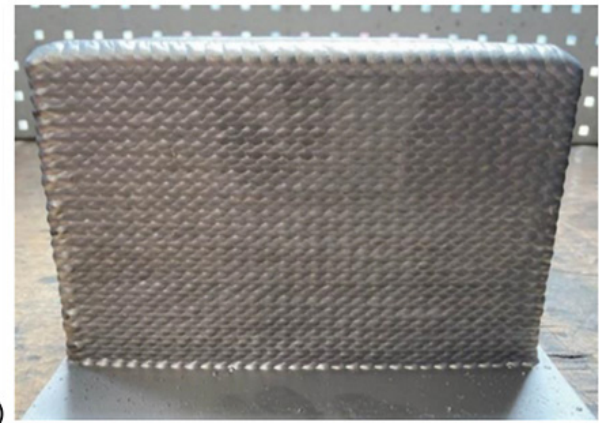

Figure 2-(a) Ti6Al4V Grade 5 and (b) Ti6Al4V Grade 23 walls

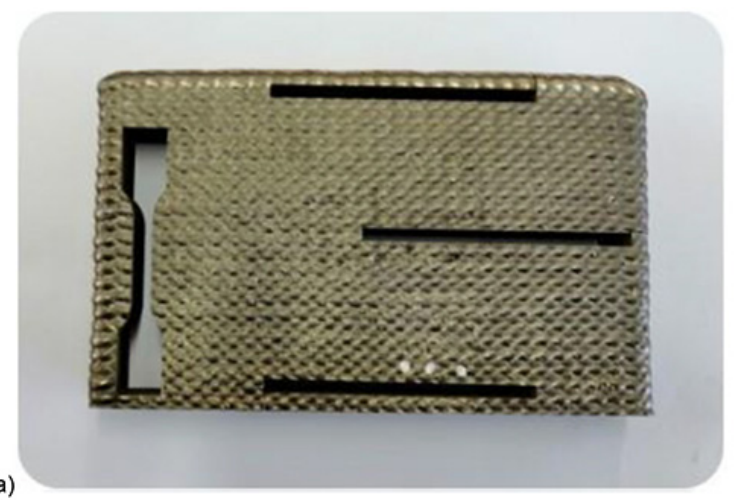

(a)

(b)

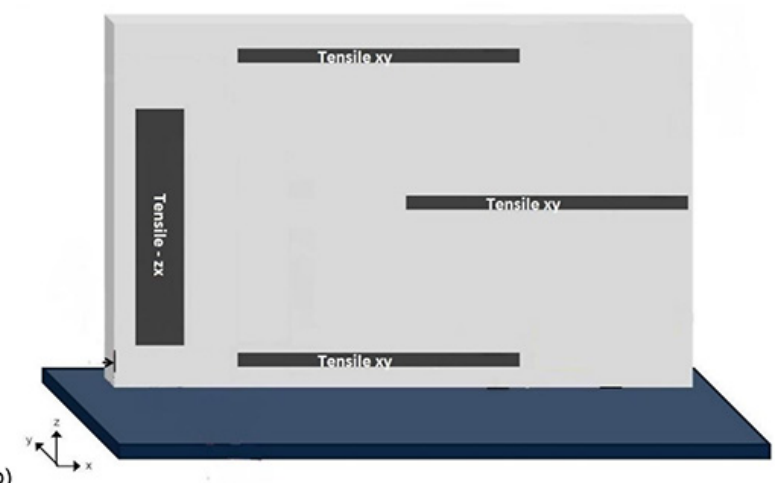

Figure 3-(a) Machined wall and (b) positions of machining of samples

shown in Figure $3 \mathrm{~b}$. The tensile samples had a gauge length of $30 \mathrm{~mm}$ and a cross-section of $6 \mathrm{~mm} \times 4 \mathrm{~mm}$. Tensile tests were conducted at a strain rate of $2 \mathrm{~mm} / \mathrm{min}$ according to ASTM E8 requirements using an MTS Criterion Model 45 instrument.

\section{Results and discussion}

\section{Tensile testing}

Figure 4 shows that Grade 5 had greater tensile $\left(R_{m}\right)$ and yield strength $\left(R_{p}\right)$ than Grade 23 and lower elongation (A25) in the ZX plane, owing to its higher concentration of interstitial elements (Table II). The horizontal XY plane had higher tensile strength than the vertical ZX plane for both grades. This was influenced by the build direction $(Z)$ of the walls, ZX being in the plane in which the walls were built and XY perpendicular to the build planes. The thermal cycle also played a role. The vertical direction was more ductile, and the difference between the two directions was greater for Grade 23. The standard deviation (SD) 


\section{Comparison of the mechanical properties of Grade 5 and Grade 23 Ti6Al4V}

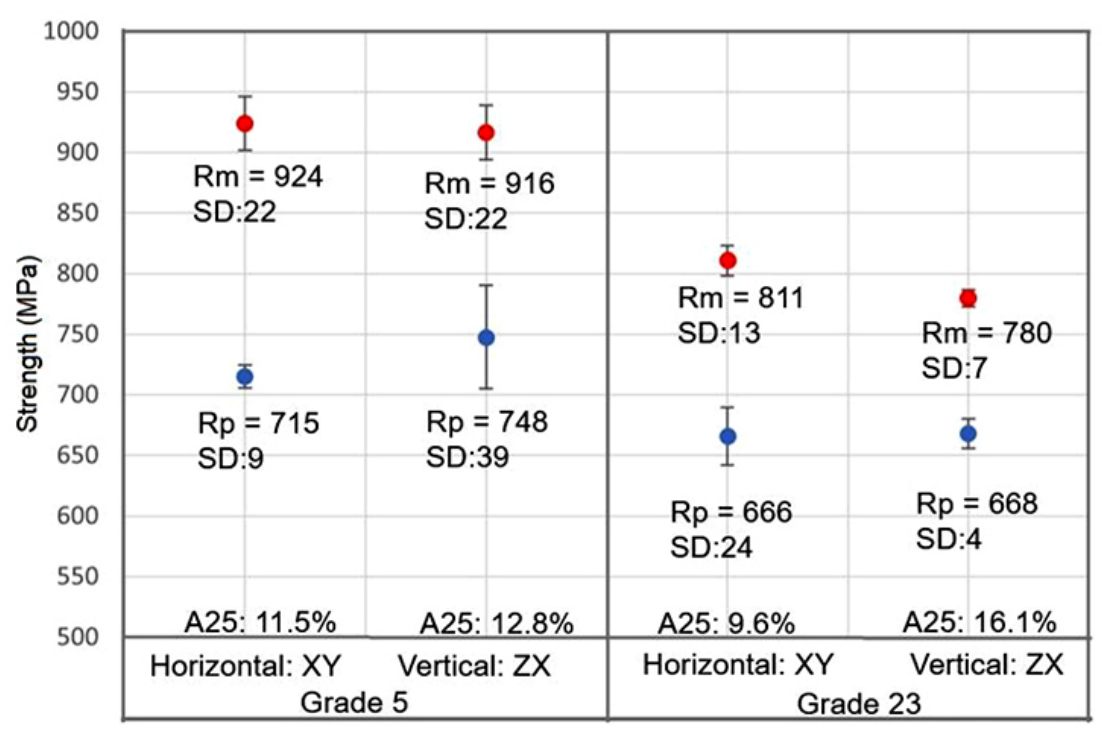

Figure 4-Ti6AI4V Grade 5 vs Grade 23 tensile test results at the horizontal XY and vertical ZX planes showing ultimate tensile strength ( $\mathbf{R}_{\mathrm{m}}$ ), $0.2 \%$ yield strength $\left(\mathbf{R}_{\mathrm{p}}\right)$, and \% elongation (A25)

(a)

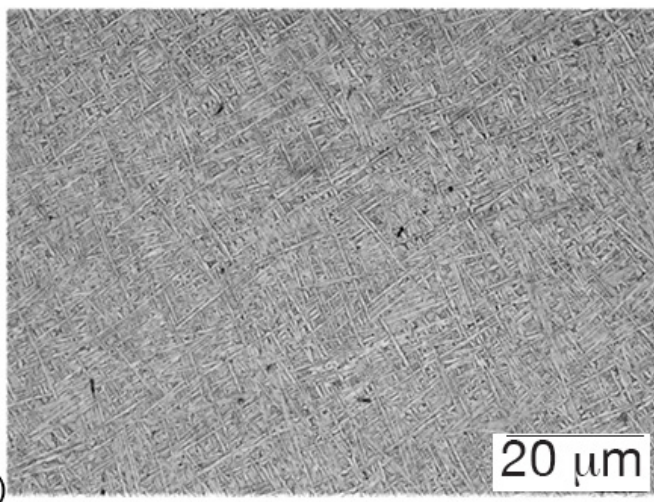

(b)

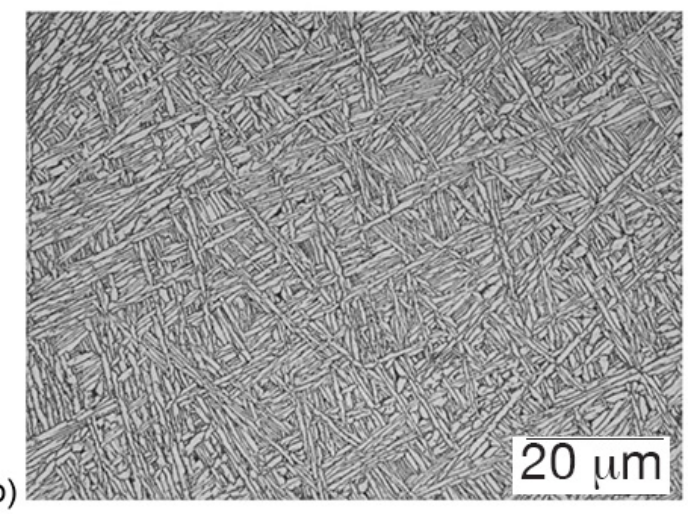

Figure 5-Grade 5 Ti6Al4V microstructures at (a) bottom and (b) top layers in the wall

(a)

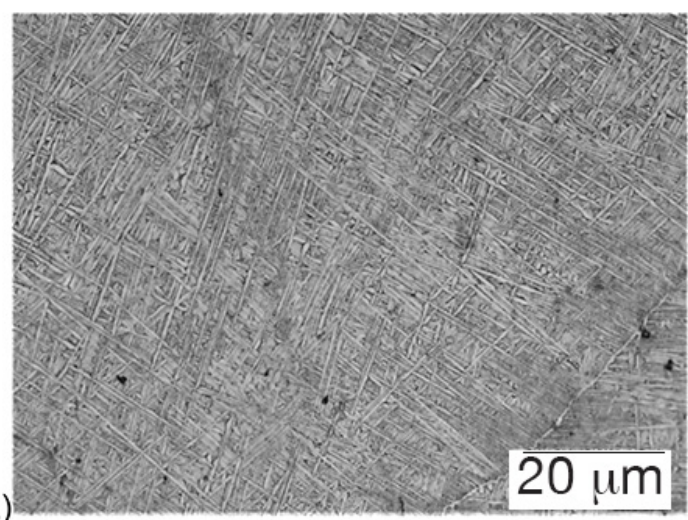

(b)

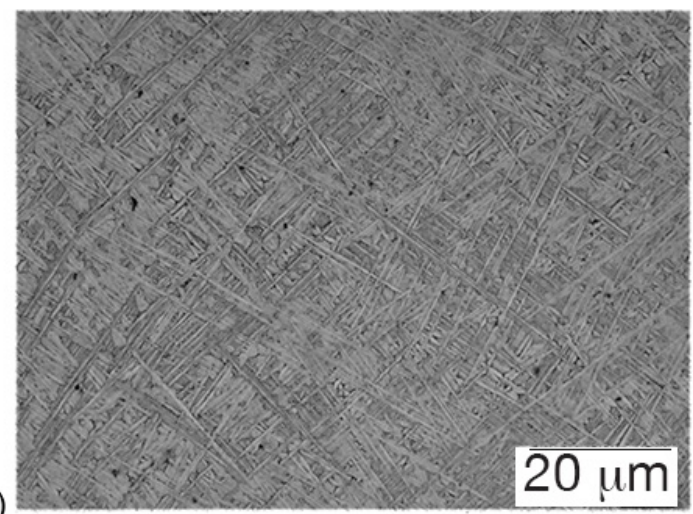

Figure 6-Grade 23 Ti6Al4V microstructures at (a) bottom and (b) top layers in the wall

indicates the range of strengths. The tensile strength differences between the two directions were $8 \mathrm{MPa}$ for Grade 5 and 31 $\mathrm{MPa}$ for Grade 23. Anisotropy was also seen in the elongation differences of the two planes of both grades of Ti6Al4V; that in the ZX plane being higher than in the XY plane.

\section{Microstructures}

Figures 5 and 6 show microstructures of samples extracted from the XY plane of the walls. Figures $5 \mathrm{a}$ and $5 \mathrm{~b}$ show the lathlike matrix structure and lamellar structures, respectively, of Grade 


\section{Comparison of the mechanical properties of Grade 5 and Grade 23 Ti6Al4V}

5 Ti6Al4V. When WAAM walls are built up from a substrate, the bottom layers are subjected to faster cooling rates, which result in martensitic plates formed into lathlike $\alpha$ structures. As additional layers are deposited on the wall, more heat accumulates, and the cooling rate is reduced (Bintao et al., 2018). Due to the increased heat accumulation, the upper layers have a fully lamellar $\alpha$ structure (Bintao et al., 2018).

The same trend is witnessed in the Grade 23 microstructures shown in Figure 6; however, Grade 23 has a lower content of interstitial elements, which means that it has fewer $\alpha$ stabilizers. Oxygen and nitrogen are known to be strong $\alpha$ stabilizers (Kazantseva et al., 2017). This resulted in smaller $\alpha$ colonies, and the structures at the top layers of Grade 23 comprise smaller $\alpha$ colonies compared with those in the Grade 5 walls.

\section{Positional differences}

Figure 7 shows the ultimate tensile strengths $\left(R_{m}\right)$ of the walls at the bottom and top layers in the XY plane. The results show that samples taken from different positions in the walls exhibited different tensile strengths: the bottom layers had higher tensile strength than the top layers. This phenomenon is influenced by the heat accumulated by the wall and the cooling rate that it was subjected to, which in turn modified the grain sizes and microstructural evolution, as shown in Figures 5 and 6.

\section{Hardness testing}

Hardness tests were carried out using the tensile samples taken in the XY plane. The results, presented in Figure 8, show that samples taken from the bottom of the walls had higher hardness than those taken from the top. This result supports the tensile data shown in Figure 7. This effect can be explained by the thermal cycle to which the walls were subjected. The hardness of Grade 5 was higher than that of Grade 23 due to its higher content of interstitial elements (Oh et al., 2011).

\section{Correlation between tensile strength and hardness}

Figure 9 shows that a linear relationship existed between the tensile strength and Vickers hardness of these WAAM Ti6Al4V alloys, with a correlation coefficient $\left(R^{2}\right)$ of 0.973 . In this hardness range, the tensile strength of Ti6Al4V alloys produced using Gefertec's 3DMP ${ }^{\circledR}$ WAAM process can be estimated by using Equation [1]:

$$
\mathrm{R}_{\mathrm{m}}(\mathrm{MPa})=4.51 \mathrm{VHN}-620
$$

\section{Conclusions}

The effect of interstitial impurities on the anisotropy of the physical properties of Grade 5 and Grade 23 Ti6Al4V alloy walls produced by WAAM was investigated. The results show that

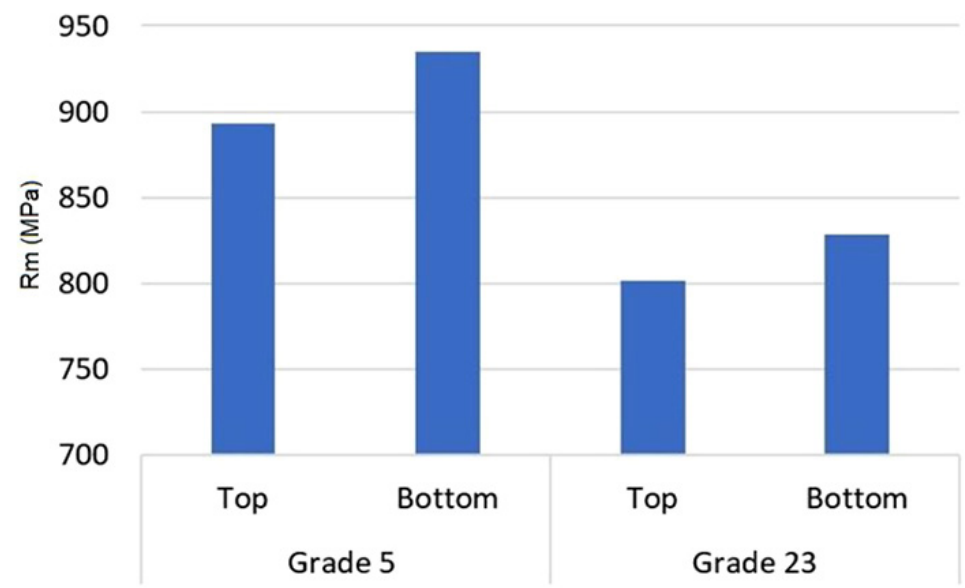

Figure 7 - Positional difference of ultimate tensile strength $\left(R_{m}\right)$ in the XY plane of Grade 5 and Grade 23 Ti6AI4V

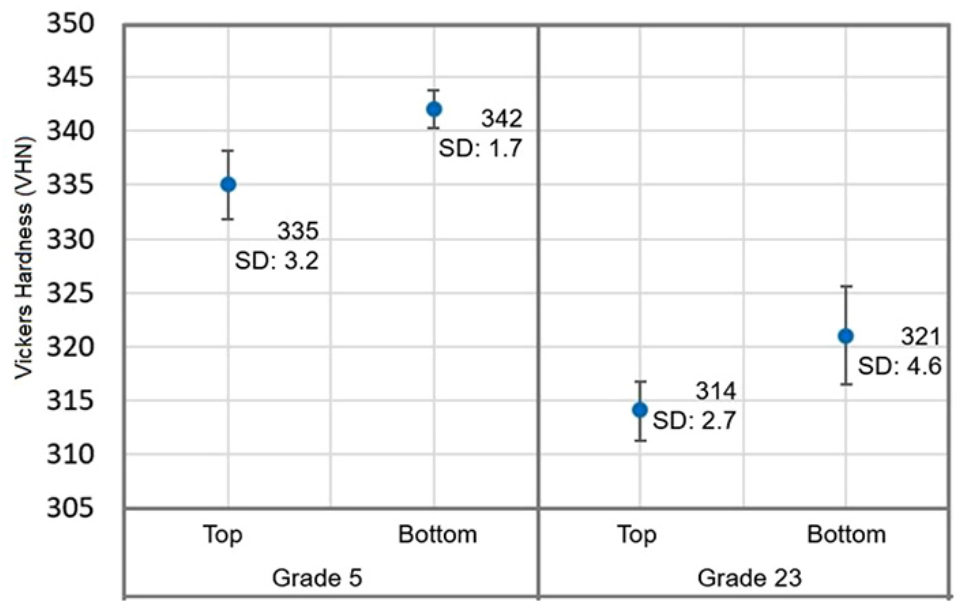

Figure 8 - Comparison of Vickers hardness of Grade 5 and Grade 23 Ti6Al4V walls at different vertical positions 


\section{Comparison of the mechanical properties of Grade 5 and Grade 23 Ti6Al4V}

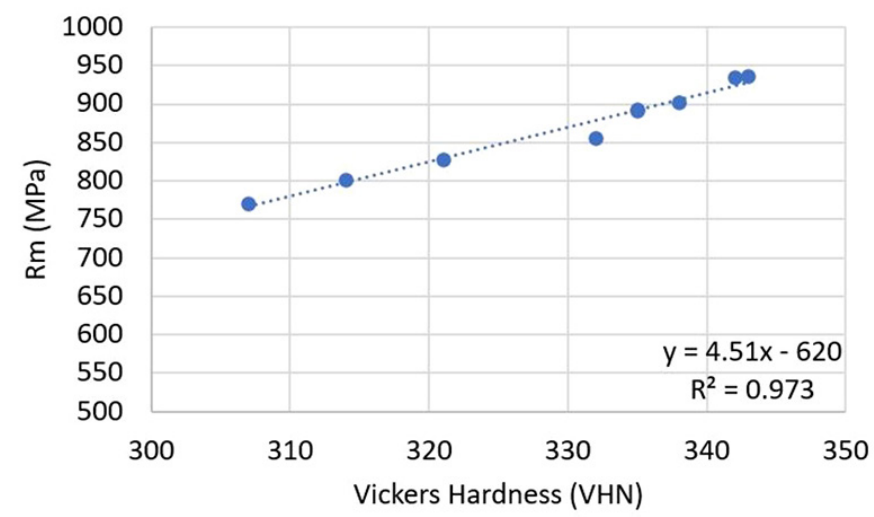

Figure 9 - Correlation between Vickers hardness and ultimate tensile strength of Ti6AI4V alloys

Grade 5, which has a high content of interstitial elements, had greater ultimate tensile strength $\left(R_{m}\right)$, greater yield strength $\left(R_{p}\right)$, and lower elongation (A25) than Grade 23. Tensile properties of both grades were slightly direction-dependent: the horizontal XY plane had higher tensile strength and lower elongation compared with the vertical ZX plane. Grade 23 displayed more marked directional differences in these properties than Grade 5 Ti6Al4V, owing to its lower content of interstitial elements. Vertical positional differences were also observed: the bottom layers of the wall had lathlike $\alpha$ structures due to the faster cooling rate at that position. As more layers were deposited and more heat accumulated in the wall, the cooling rate was reduced, which gives rise to lamellar $\alpha$ structures in the top layers. The heat accumulation and differences in cooling rates resulted in higher tensile strength and lower elongation in the bottom layers. A good correlation between the ultimate tensile strength and Vickers hardness was observed.

\section{Acknowledgements}

Gefertec GmbH is thanked for supplying the Ti6Al4V walls used in this project. Mr Pierre Rossouw (CSIR) assisted with the heat treatment. Sincere gratitude is directed to Mr Sibusiso Mahlalela and $\mathrm{Mr}$ Kabelo Matea for assisting with the experimental work. Professor Kathy Sole is thanked for proofreading the article.

\section{Authors' contributions}

Christof Gassmann: preparation and printing of Ti6Al4V walls, results interpretation, and supervision. Heinrich Möller: arranged samples, experimental tests, and supervision. Lesego Mashigo: sample preparation, optical analysis, tensile and hardness testing, and the first draft of this article.

\section{References}

AMFG. 2018. Autonomous manufacturing. https://amfg.ai/2018/05/17/anintroduction-to-wire-arc-additive-manufacturing/?cn-reloaded=1 [accessed 17 March 2020].

AnTonysamy, A.A. 2012. Microstructure, texture and mechanical property evolution during additive manufacturing of Ti6Al4V alloy for aerospace applications. PhD thesis, Manchester University, UK.

Azom. 2002. Azo Materials. https://www.azom.com/article.aspx?ArticleID=1547 [accessed 12 April 2020].

Bauristhene, A.M., Mutombo, K., and StumpF, W.E. 2013. Alpha case formation mechanism in Ti-6Al-4V alloy investment castings using YFSZ shell moulds. Journal of the Southern African Institute of Mining and Metallurgy, vol. 113. pp. 357-361.
BENson, J.M. 2012. Safety considerations when handling metal powders. Journal of the Southern African Institute of Mining and Metallurgy, vol. 112, no. 7. pp. 563-575.

Bermingham, M., McDonald, S., And Dargusch, M. 2018. Effect of trace lanthanum hexaboride and boron additions on microstructure, tensile properties and anisotropy of Ti-6Al-4V produced by additive manufacturing. Materials Science and Engineering, vol. 719. pp. 1-11.

Bintao, W., Zengxi, P., Donghong, D., Dominic, C., and Huijun, L. 2018. Effects of heat accumulation on microstructure and mechanical properties of Ti6Al4V alloy deposited by wire arc additive manufacturing. Additive Manufacturing, vol. 23. pp. 151-160.

Biswal, R., Zhang, X., Syed, A. K., Awd, M., Ding, J., Walther, F., and Williams, S. 2019. Criticality of porosity defects on the fatigue performance of wire + arc additive manufactured titanium alloy. International Journal of Fatigue, vol. 122. pp. 208-217.

Carroll, B., Palmer, T., and Beese, A. 2015. Anisotropic tensile behavior of Ti-6Al-4V components fabricated with directed energy deposition additive manufacturing. Acta Materialia, vol. 87. pp. 309-320.

GeFertec. 2020. Gefertec GmbH. https://www.gefertec.de/en/3dmp-process/ [accessed 1 March 2020].

Kazantseva, N., Krakhmalev, P., Yadroitsev, I., Fefelov, A., Merkushev, A., Luyinikh, M., and KuRENNYK, T. 2017. Oxygen and nitrogen concentrations in the Ti-6Al-4V alloy manufactured by direct metal laser sintering (DMLS) process. Materials Letters, vol. 209. pp. 311-314.

Li, J.L., Alkahari, M.R., Rosli, N.A., Hassan, R., Sudin, M.N., and Ramli, F.R. 2019. Review of wire arc additive manufacturing. International Journal of Automation Technology, vol. 13, no. 3. pp. 346-353.

Oн, J.M., LeE, B.G., Сно, S.W., LeE, S.W., Cно, G.S., and Lim, J.W. 2011. Oxygen effects on the mechanical properties and lattice strain of Ti and Ti-6Al-4V. Metals and Materials International, vol. 17, no. 5. pp. 733-736.

Thuketana, S., Taute, C., Möller, H., and du Plessis, A. 2020. Characterization of surface roughness and subsurface pores and their effect on corrosion. Journal of the Southern African Institute of Mining and Metallurgy, vol. 120. pp. 369-376.

Wang, F., Williams, S., Colegrove, P., and Antonysamy, A.A. 2012. Microstructure and mechanical properties of wire and arc additive manufactured Ti-6Al-4V. Metallurgical and Materials Transactions A, vol. 44. pp. 968-977.

Wu, B., Pana, Z., Lib, S., Cuivisa, D., Dingc, D., and Li, H. 2018. The anisotropic corrosion behaviour of wire arc additive manufactured Ti-6Al-4V alloy in 3.5\% NaCl solution. Corrosion Science, vol. 137. pp. 176-183.

Zhang, X., Martina, F., Ding, J., Wang, X., and Williams, S.W. 2016. Fracture toughness and fatigue crack growth rate properties in wire +arc additive manufactured Ti-6Al-4V. Fatigue and Fracture of Engineering Materials and Structures, vol. 40, no 5. pp. 790-803. 